\title{
PENGELOLAAN KELAS DAN PENGGUNAAN BAHASA DALAM PENGAJARAN BAHASA INGGRIS DI RUBIK BOJONG GEDE DAN L COURSE TAJUR HALANG KABUPATEN BOGOR
}

\author{
Euis Kurniasih, Saidatun Nafisah, Devi Mulyani \\ Program Studi Pendidikan Bahasa Inggris, Fakultas Bahasa dan Seni, Universitas Indraprasta PGRI \\ euis99@gmail.com, saida.unindra@gmail.com,mulyadevi@yahoo.com
}

\begin{abstract}
Abstrak
Pengabdian masyarakat ini bertujuan untuk memberikan pelatihan kepada pengajar di Rubik Bojong Gede dan L Course Tajur Halang mengenai pengelolaan kelas dan penggunaan bahasa dalam pengajaran bahasa Inggris untuk anak-anak. Pengelolaan kelas meliputi karakteristik anak-anak, penataan posisi duduk, pengelompokan siswa, media pengajaran, dan perencanaan pengajaran sedangkan penggunaan bahasa meliputi ekspresi bahasa yang digunakan dalam setiap tahap kegiatan pembelajaran. Pelaksanaan pengabdian masyarakat ini menggunakan beberapa metode yaitu presentasi, diskusi, praktik mengajar dan evaluasi. Melalui pelatihan yang diberikan, para peserta dapat meningkatkan kompetensi dalam mengajar bahasa Inggris untuk anak-anak.
\end{abstract}

Keywords: pengelolaan kelas, penggunaan bahasa, pengajaran bahasa Inggris

\begin{abstract}
The community service aims to give the training to the teachers of Rubik Bojong Gede and L Course Tajur Halang about the classroom management and language use in teaching English to children. The scope of classroom management covers the charateristics of children, seating arrangement, grouping students, teaching media and instructional planning; while the language use elaborates the language expressions use in every steps of learning activities. The community service was conducted by some methods such as presentation, discussion, teaching practice and evaluation. The training made the participats enhance their knowledge and competence in teaching English to children.
\end{abstract}

Keywords: classroom management, language use,teaching English

\section{PENDAHULUAN}

Pembelajaran bahasa Inggris di Indonesia sudah banyak dilakukan baik melalui pendidikan formal di sekolah ataupun pendidikan non formal di luar sekolah, bahkan diajarkan semenjak usia dini. Hal tersebut dilakukan untuk menjawab tantangan globalisasi yang sudah tidak bisa terhindarkan lagi. Seperti yang dinyatakan oleh Alwasilah (1997) bahwa tanpa kemapuan bahasa Inggris masyarakat Indonesia akan mendapatkan kesulitan bersaing dengan masyarakat global. Penyelenggaraan pembelajaran bahasa Inggris yang dilakukan melalui pendidikan non formal sangat beragam mulai dari lembaga kursus sampai dengan komunitas-komunitas yang peduli terhadap pendidikan.

Rumah Belajar Indonesia Kreatif (Rubik) adalah program pengajaran bagi 
anak-anak dhuafa yang dibentuk oleh Yayasan Gema Insani pada tahun 2010. Rubik membuka beberapa kelas di tempat yang berbeda salah satunya berada di Kampung Lio Bojong Gede. Program pengajaran ini dilaksanan setiap hari Minggu dari pukul dua siang sampai dengan pukul lima sore. Siswa Rubik sebagian besar adalah anak-anak Sekolah Dasar (SD) dan pelajaran yang diberikan salah satunya adalah bahasa Inggris.

Para relawan pengajar sebanyak 15 orang adalah para mahasiswa yang berasal dari berbagai perguruan tinggi negeri dan swasta yang ada di Jakarta. Sebagian besar relawan berasal dari jurusan non bahasa Inggris.

Penyelenggara program nonformal pengajaran Bahasa Inggris lainnya adalah L Course. L Course merupakan sebuah lembaga kursus dan bimbingan belajar untuk anak-anak usia sekolah dasar yang berada di Tajur Halang Kabupaten Bogor. Menurut pengelola kursus, animo anak-anak untuk mengikuti kursus bahasa Inggris semakin besar ditunjukkan dengan bertambahnya jumlah peserta kursus setiap semester. Namun latar belakang pengajarnya hanya SMA dan kursus bahasa Inggris sehingga dalam penyelenggaraan pembelajaran bahasa Inggris baik Rubik maupun L. Course memiliki permasalahan yang sama yaitu para pengajarnya memerlukan pelatihan pengajaran bahasa Inggris terutama yang berhubungan dengan teori-teori pengelolaan kelas dan juga penggunaan bahasa-bahasa Inggris yang dapat diterapkan pada anak-anak. Selama ini, mereka hanya memperkenalkan kosakata dan menyuruh anak mengucapkannya. Padahal peran guru sebagai role model bagi anak-anak sangat ditunjang oleh pengetahuan mereka tentang strategi pengelolaan kelas dan penggunaan bahasa oleh guru kepada siswa.
Selain itu menurut Suyatno (2015), sebagai pengajar, pendidik dituntut untuk menciptakan kegiatan pembelajaran yang optimal. Maka, solusi permasalahan yang dihadapi oleh Rubik dan L Course untuk meningkatkan kualitas guru dalam melaksanakan pengajaran Bahasa Inggris untuk anakanak adalah dengan penyelenggaraan kegiatan pelatihan pengelolaan kelas dan penggunaan bahasa kelas (classroom English). Menurut Bosch (2016:2), pengelolaan kelas merupakan gambaran bagaimana guru dan siswa bekerja bersama dan bagaimana guru menciptakan suasana kelas yang dapat membuat siswa dapat memahami materi pelajaran dan menikmati proses pengajaran. Weinstein dan Weber (2011: 222) lebih jauh mengelaborasi 5 tugas dalam pengelolaan kelas antara lain: (1) mendesain lingkungan fisik kelas dengen menyediakan sumber belajar yang mudah diakses, (2) membangun relasi positif antara guru dan siswa dengan menjalin komunikasi yang ramah antara guru dan siswa, (3) memelihara atmosfir komunitas kelas dengan menyediakan kesempatan seluas-luasnya kepada siswa untuk menerapkan bekerjasama dalam proses pembelajaran, (4) mengajarkan norma berperilaku dengan praktik saling menghormati sesama teman, (5) merespon perilaku yang kurang baik dengan cara yang halus misalnya dengan diam ataupun dengan tatapan mata.

Dalam prakteknya, pengelolaan kelas sangat berkaitan erat dengan bagaimana guru menggunakan bahasabahasa kelas berupa instruksi-instruksi sederhana yang mudah ditangkap oleh siswa. Peranan bahasa kelas untuk mewujudkan interaksi merupakan aspek yang sangat krusial dalam suksesnya penyelenggaraan pembelajaran (Hughes, 1990:3). Pengajar bahasa Inggris memerlukan pelatihan penggunaan bahasa kelas karena bahasa 
merupakan medium instruksi. Selain itu bahasa yang mereka gunakan akan menjadi role model bagi siswanya. Hughes (1990: 6-7) menjelaskan secara lebih rinci alasan mengapa pelatihan penggunaan bahasa kelas sangat penting dilakukan yaitu: (1) bahasa merupakan alat komunikasi sehingga melalui bahasa siswa dapat berpartisipasi dalam kegiatan kelas, mengetahui apa yang harus dilakukan, (2) bahasa diujarkan dengan mulut oleh para siswa sehingga dengan menggunakan bahasa artinya melakukan praktek produksi ujaran, (3) penggunaan bahasa kelas akan menggambarkan situasi dan prosedur pengajaran yang diberikan oleh guru kepada siswa, (4) masih ada keyakinan bahwa siswa pada usia awal sekolah harus belajar untuk mengucapkan kata, frasa ataupun kalimat apapun.

Dari paparan tersebut dapat kita ketahui bahwa pengetahuan pengelolaan kelas dan juga penggunaan bahasa kelas sangat penting untuk dimiliki oleh guru. Bahkan, ada sebuah hasil penelitian yang menunjukkan bahwa dengan mengombinasikan variasi strategi mengajar dan peran guru yang sesuai dengan kegiatan belajar mengajar, kelas dapat diatur dengan baik dan dapat dilihat keefektifannya melalui situasi belajar dan kualitas proses belajar dan mengajar (Artini dkk: 2013). Maka, kegiatan pengabdian masyarakat dengan judul pengelolaan kelas dan penggunaan bahasa dalam pengajaran bahasa Inggris di Rubik dan L Course diharapkan kualitas pengajar dapat ditingkatkan dan kemampuan berbahasa siswa menjadi semakin baik.

\section{METODE PELAKSANAAN}

Kegiatan pengabdian masyarakat ini dilaksanakan pada Desember 2017 setiap hari Minggu pukul 14.00 selama 1,5 - 2 jam di Rubik Bojong Gede.
Metode yang dilakukan dalam kegiatan pengabdian masyarakat ini adalah presentasi, diskusi, praktek mengajar dan evaluasi.

\section{HASIL DAN PEMBAHASAN}

Kegiatan pengabdian masyarakat yang dilakukan di Bojong Gede ini menghasilkan luaran berupa modul dan artikel ilmiah. Modul yang disusun terdiri dari 14 halaman yang mencakup definisi pengelolaan kelas, karakteristik anak-anak, penataan posisi duduk, pengelompokan siswa, media pengajaran, perencanaan pengajaran dan penggunaan bahasa kelas (classroom language). Modul tersebut telah dibagikan kepada peserta dan dijadikan panduan praktek mengajar. Artikel ilmiah disusun berdasarkan laporan hasil pelaksanaan program kemitraan masyarakat, lalu akan diajukan pada pengelola jurnal pengabdian masyarakat yang berISSN.

Modul yang disusun dipresentasikan pada pertemuan pertama dan kedua berisi tentang pengelolaan kelas dan penggunaan bahasa kelas (classroom English) sedangkan artikel ilmiah disusun setelah laporan pengabdian masyarakat selesai.

Sebelum presentasi dimulai, pengelola Rubik membuka acara dengan perkenalan masing-masing peserta dan pembicara serta mengutarakan maksud dan tujuan kegiatan.

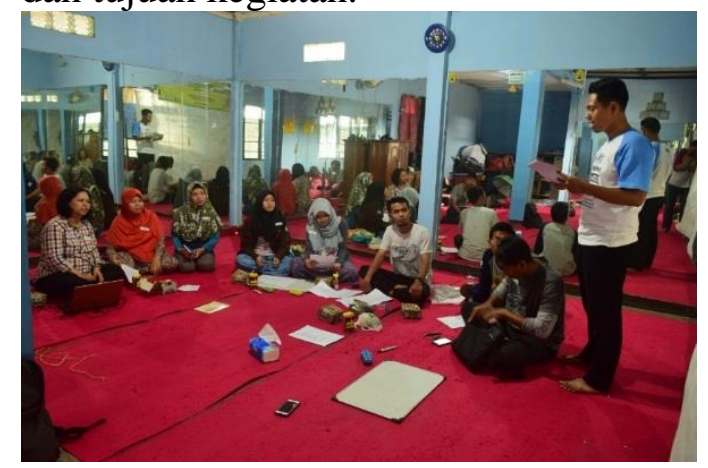




\section{Pengelolaan Kelas}

Kegiatan pada pertemuan pertama adalah pemaparan dan diskusi tentang pengelolaan kelas. Pemaparan tentang pengelolaan kelas meliputi cakupan pengelolaan kelas secara umum, karakteristik anak-anak, penataan posisi duduk, pengelompokan siswa, media pengajaran, dan perencanaan pengajaran. Setelah pemaparan dilanjutkan dengan diskusi. Diskusi yang dilakukan bersifat cair dengan sharing pengalaman tim dosen dan para peserta dalam mengajar anak-anak. Pertanyaan meliputi penanganan terhadap anak yang susah fokus dan banyak gerak dan juga kurangnya minat siswa belajar bahasa Inggris.

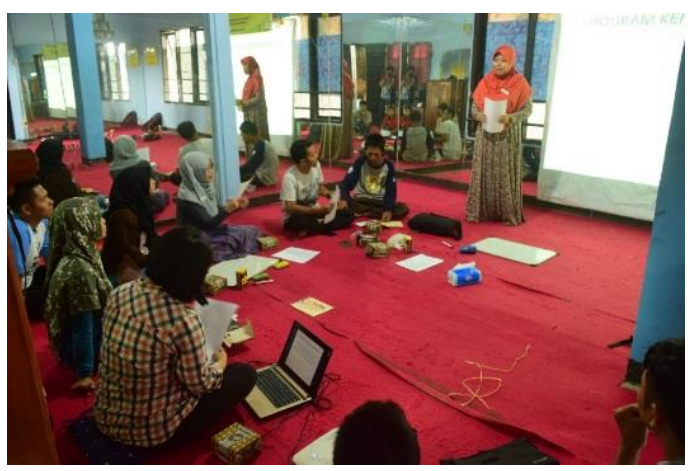

\section{Penggunaan Bahasa}

Kegiatan pada pertemuan kedua adalah pemaparan dan diskusi tentang penggunaan bahasa kelas (classroom English). Bahasa kelas merupakan ekspresi-ekspresi bahasa yang digunakan dalam berkomunikasi antara pengajar dan siswa. Penggunaan bahasa kelas menjadi bagian dari praktek pengelolaan kelas bahasa Inggris. Pemanfaatan bahasa kelas oleh guru sangat penting dalam proses belajar mengajar di kelas agar anak-anak terbiasa dalam menggunakan ekspresi-ekspresi bahasa Inggris dalam berinteraksi. Ekspresiekspresi bahasa kelas yang digunakan biasanya berbentuk ujaran pendek dan sederhana yang dapat dengan mudah dipraktekan oleh guru dalam setiap tahapan pengajaran yaitu kegiatan awal, kegiatan inti dan kegiatan akhir.

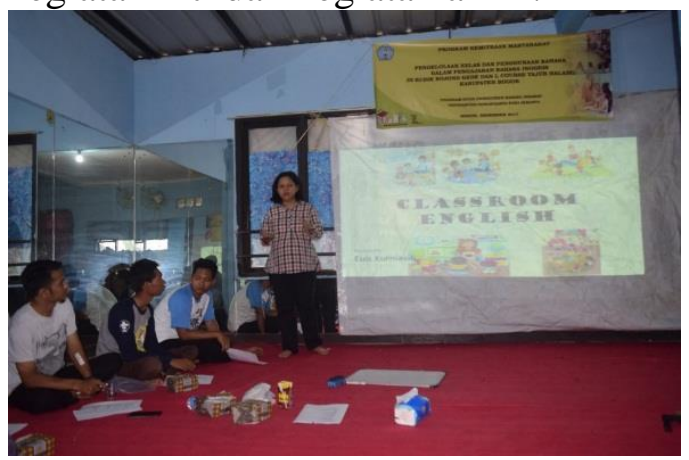

Dalam kegiatan awal ekspresi yang dapat digunakan meliputi kegiatan menyapa, menanyakan kabar, perkenalan, memulai kegiatan pembelajaran, pengkondisian kesiapan siswa dalam memulai pelajaran, memeriksa kehadiran siswa, jika ada siswa yang terlambat datang. Untuk kegiatan inti, ekspresi bahasa yang digunakan meliputi berbagai kegiatan seperti memberikan instruksi, perpindahan sesi, metabahasa, perujukan, permintaan maaf, berterima kasih, peringatan, perilaku afektif, memberikan umpan balik. Instruksi yang diberikan kepada siswa berkaitan dengan berbagai kegiatan seperti penggunaan buku ajar, penggunaan papan tulis, kegiatan listening, penggunaan gambar, permainan, lagu, kinestetik, pembagian kelompok, dan peniruan (imitasi). Dalam kegiatan akhir ekspresi bahasa yang digunakan meliputi mengakhiri sesi mengajar, belum saatnya mengakhiri sesi mengajar, meminta siswa menunggu, perpindahan sesi mengajar, pekerjaan rumah, mengucapkan salam perpisahan dan meninggalkan ruangan.

Setelah pemaparan, diskusi diisi dengan praktik pengucapan ekspresi bahasa secara bergantian dan serentak serta memastikan pengucapannya benar. Mereka memiliki banyak pilihan untuk menggunakan ekspresi bahasa dalam setiap sesi mengajar yang belum mereka ketahui sebelumnya. Kemudian untuk persiapan pertemuan ketiga peserta 
dibagi dua kelompok. Satu kelompok terdiri dari lima atau empat orang. Masing-masing kelompok diberi tugas untuk mempersiapkan praktek mengajar dan menerapkan teori pengelolaan dan penggunaan bahasa kelas.

\section{Praktik Mengajar}

Kegiatan pada pertemuan ketiga adalah praktek mengajar. Dari dua kelompok yang sudah dibentuk, peserta yang datang hanya satu kelompok sehingga yang tampil untuk praktek mengajar hanya satu kelompok. Anggota kelompok berbagi peran ada yang menerangkan, ada yang memegang papan tulis kecil dan sisanya memastikan sesuai siswa memperhatikan penjelasan. Materi yang mereka sampaikan adalah tentang family. Kosakata yang diperkenalkan kepada siswa yaitu mother, father, sister dan brother. Selain itu, siswa juga diperkenalkan dengan ujaran "how many people are in your family" dan jawabannya "they are ... members". Siswa diminta untuk menirukan apa yang diucapkan. Lalu dipraktekan secara berpasangan. Setelah itu diminta perwakilan untuk mempraktekan di depan kelas.

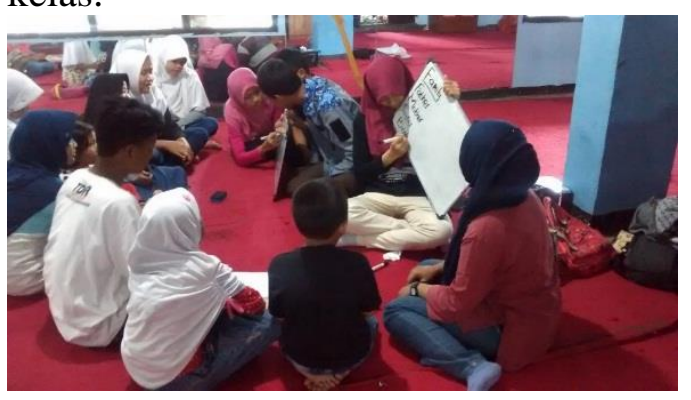

\section{Evaluasi}

Pertemuan keempat adalah evaluasi praktek mengajar yang sudah dilaksanakan pada sesi sebelumnya. Evaluasi dilakukan dengan sama-sama mengulas apa yang sudah mereka lalukan ketika mengajar mulai dari kegiatan awal, kegiatan inti sampai dengan kegiatan akhir. Ketika kegiatan awal, yang mereka lakukan adalah menyapa dan menyampaikan apa yang akan diajarkan. Dari kegiatan awal tersebut evaluasinya adalah bagaimana melakukan brainstorming yang menarik yaitu bisa dengan gambar atau dengan permainan. Evaluasi untuk kegiatan inti antara lain penggunaan media sebaiknya tidak hanya terbatas pada whiteboard kecil tetapi lebih menarik jika disajikan gambar atau video. Kerjasama dalam membimbing anak sudah bagus namun ada ujaran-ujaran yang salah seperti 'are you have a question?' seharusnya 'do you have a question' atau cukup hanya 'any question?' Setiap pengajar harus memastikan ujaran yang mereka gunakan betul secara grammar karena akan diikuti oleh siswanya. Selain itu, materi dapat diulang-ulang namun diterapkan dengan strategi yang berbeda. Hal tersebut bagus untuk penyerapan pemahaman yang mendalam dan akan mudah masuk memori jangka panjang mereka. Anak-anak akan lebih mudah memahami hal-hal yang kongkrit. Akan lebih baik lagi jika mereka membuat persiapan mengajar dengan membuat lesson plan yang dilengkapi dengan skenario ekspresi bahasa yang digunakan dalam setiap sesi pengajaran.

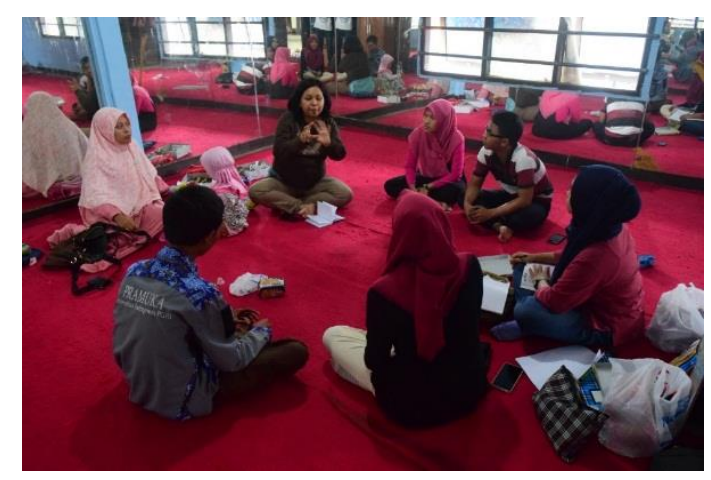

\section{SIMPULAN}

Pengelolaan kelas dan penggunaan bahasa dalam pengajaran bahasa Inggris untuk anak-anak merupakan keterampilan yang sebaiknya dikuasai oleh para 
pengajar. Karakteristik pebelajar anakanak dan dewasa itu berbeda sehingga perlu perlakuan yang sesuai dengan perkembangan mereka. Pengetahuan tentang karakteristik anak-anak serta bagaimana mengorganisir kegiatan belajar mengajar melalui persiapan mengajar yang matang, media pengajaran yang menarik dan pengelompokan siswa yang tepat akan membuat suasana belajar yang nyaman dan dinamis. Penggunaan bahasa kelas (classroom English) dalam setiap sesi kegiatan belajar akan menjadi comprehensible input bagi siswanya sehingga siswa sudah terbiasa dengan ekspresi bahasa tersebut sehingga dapat memahami dan menerapkannya. Maka, pengetahuan tentang pengelolaan kelas dan penggunaan bahasa akan membuat pengajar menjadi semakin memiliki kompetensi.

\section{DAFTAR PUSTAKA}

Alwasilah, A. C. (2007). CTL menjadikan kegiatan belajar mengasyikan dan bermakna. Bandung: Mizan Learning Centre
Bosch, K. (2016). Planning classroom management: A Five-Step Process to Creating a Positive Learning Environment $2^{\text {nd }} E d$. Thousand Oaks:Corwin Press.

Hughes, G. (1990). A handbook of classroom English. Hongkong: Oxford University Press.

Pratiwi, N.K.P.,Artini, L.P \& Adnyani, L.D.S. (2013) The implementation of instructional strategies and teacher's roles in classroom management in TK Santi Kumara. Jurnal Pendidikan Bahasa Inggris Undiksa Vol 1 No.1

Suyatno. (2015). Kinerja profesi pendidik masa kini. DEIKSIS Jurnal Ilmiah Bahasa dan Seni Vol.07 No.03

Weinstein, C. \& Weber, W.A. (2011). Classroom management. Dalam Cooper, J.M. (editor), Classroom teaching skill (halaman 215-250). Belcomont: Wadsworth Cengage Learning 